\title{
Preoperative bone health assessment and optimization in spine surgery
}

\author{
Paul A. Anderson, MD, ${ }^{1}$ Aamir Kadri, MS, ${ }^{1}$ Kristyn J. Hare, PA-C, ${ }^{1}$ and Neil Binkley, MD ${ }^{2}$ \\ 1'Department of Orthopedics and Rehabilitation, University of Wisconsin, Madison; and 2University of Wisconsin School of \\ Medicine and Public Health, Osteoporosis Clinical Research Program, Madison, Wisconsin
}

OBJECTIVE The purpose of this investigation was to characterize the bone health in preoperative spine surgery patients. This information will provide a framework to understand the needs and methods for providing bone health optimization in elective spine surgery patients.

METHODS A retrospective study of 104 patients undergoing bone health optimization was performed. Patients were selected based on risk factors identified by the surgeon and suspected compromised bone health. Evaluation included history and examination, laboratory investigations, and bone mineral density (BMD) at 3 sites (femoral neck, lumbar spine, and radius). Patients' bone status was classified using WHO criteria and expanded criteria recommended by the National Osteoporosis Foundation (NOF). The 10-year Fracture Risk Assessment Tool (FRAX) scores of the hip and major osteoporotic fracture (MOF) were calculated with and without femoral neck BMD, with spine BMD, and with the trabecular bone score (TBS). Antiresorptive and anabolic agents were provided in accordance with meeting NOF criteria for treatment of osteoporosis.

RESULTS The mean patient age was 69.0 years, and $81 \%$ of patients were female. The mean historical height loss was $5.6 \mathrm{~cm}$, and $54 \%$ of patients had a history of fracture. Secondary osteoporosis due to chronic renal failure, inflammatory arthritis, diabetes, and steroid use was common (51\%). The mean 25 -hydroxy vitamin D was $42.4 \mathrm{ng} / \mathrm{ml}$ and was normal in $81 \%$ of patients, with only 4 patients being deficient. The mean T-scores were -2.09 (SD 0.71) of the femoral neck, -0.54 (1.71) of the lumbar spine, and -1.65 (1.38) of the distal radius. These were significantly different. The 10-year FRAX MOF score was $20.7 \%$, and that for hip fracture was $6.9 \%$ using the femoral neck BMD and was not significantly different without the use of BMD. The FRAX risk-adjusted score using the lumbar spine BMD and TBS was significantly lower than that for the hip. Osteoporosis was present in $32.1 \%$ according to WHO criteria compared with $81.6 \%$ according to NOF criteria. Antiresorptive medications were recommended in 31 patients and anabolic medications in 44 patients.

CONCLUSIONS Surgeons can reliably identify patients with poor bone health by using simple criteria, including historical height loss, history of fracture, comorbidities associated with osteoporosis, analysis of available imaging, and calculation of FRAX score without BMD. High-risk patients should have BMD testing and bone health assessment. In patients with osteoporosis, a comprehensive preoperative bone health assessment is recommended and, if warranted, pharmacological treatment should be started.

https://thejns.org/doi/abs/10.3171/2020.5.FOCUS20255

KEYWORDS bone health optimization; spinal surgery; osteoporosis; FRAX; dual energy x-ray absorptiometry; fragility fracture

$\mathrm{O}$ PTIMIZATION of medical conditions before spine surgery is increasingly being performed to maximize outcomes, reduce the risk of adverse events, and improve efficiency. The most commonly targeted conditions, such as obesity, glucose control, and elimination of smoking, are optimized to prevent surgical site infections; modifiable cardiovascular risk factors to reduce mortality; and, more recently, reduction of preoperative opioid consumption and resetting of patient expectations to improve overall pain management. ${ }^{1-3}$ Additionally, teamwork, multidisciplinary care, and protocols are effective in improving care of complex spine patients. ${ }^{2,4}$

ABBREVIATIONS BHO = bone health optimization; BMD = bone mineral density; DXA = dual-energy x-ray absorptiometry; FRAX = Fracture Risk Assessment Tool; HU = Hounsfield units; MOF = major osteoporotic fracture; NOF = National Osteoporosis Foundation; TBS = trabecular bone score; VFA = vertebral fracture assessment; 25(OH)D = 25-hydroxy vitamin D.

ACCOMPANYING EDITORIAL DOI: 10.3171/2020.5.FOCUS20414.

SUBMITTED March 29, 2020. ACCEPTED May 13, 2020.

INCLUDE WHEN CITING DOI: 10.3171/2020.5.FOCUS20255. 
Although spine surgery involves bone dissection, removal, fixation, or the biological process of fusion, bone health is rarely considered preoperatively, and available optimization strategies are not widely applied. Dipaola et al. surveyed 86 spine surgeons who reported that only $60 \%$ evaluated bone mineral density (BMD) after fragility fracture and $40 \%$ before a spine fusion, and $18 \%$ assessed for metabolic abnormalities. ${ }^{5}$ Kuprys et al. evaluated bone health assessment over time in spinal deformity surgery patients. They found that there was an increased discussion in office notes but no change in bone interventions. ${ }^{6}$

Osteoporosis is common in patients undergoing spine surgery and is often undiagnosed. Schmidt et al. evaluated 144 spine surgery candidates older than 50 years and found that $27 \%$ had osteoporosis, $37.5 \%$ had evidence of prior fracture (most were occult vertebral fractures), and 75\% were vitamin D deficient. ${ }^{7}$ Bjerke et al. performed dual-energy x-ray absorptiometry (DXA) in 140 patients having lumbar fusion and found that $10 \%$ had osteoporosis and 58.6\% had osteopenia. ${ }^{8}$ Thus, while low bone density is common preoperatively in spine surgery patients, the role of osteoporosis assessment in preoperative care remains unknown, as few studies have evaluated the systematic application of bone health assessment/optimization to elective surgery populations.

Bone health optimization (BHO) is a comprehensive program aimed at improving $\mathrm{BMD}$, correcting modifiable factors related to bone health, and stimulating osteoblastic activity in the skeleton to condition the spine to optimize recovery after surgery. ${ }^{9}$ Several proposed guidelines for primary osteoporosis treatment and secondary fracture prevention can be adopted to identify patients who should have bone density measurement and laboratory testing and, when indicated, receive medical treatment before undergoing spinal surgery. ${ }^{10-12}$ We hypothesize that poor bone health is common in elective surgery patients and that many meet criteria for medical therapy. The purpose of this article was to characterize spine surgery patients who have been referred to the University of Wisconsin's $\mathrm{BHO}$ program. This study will provide a framework for understanding the complexity of evaluation and treatment protocols, how this care might be applied, and the severity of bone disease that is present in typical elective surgical patients.

\section{Methods}

\section{Patient Cohort}

This retrospective study included 104 spine surgery candidates who were referred to the University of Wisconsin BHO clinic from September 2017 to March 2019. Patients were referred by their surgeons as potentially having osteoporosis based on the presence of known risk factors, evaluation of opportunistic CT, use of medications known to cause bone loss, prior diagnosis of osteoporosis, and a history of prevalent fractures. The inclusion criteria were that patients were 50 years of age or older and had planned thoracolumbar surgery. This study was approved and exempt from obtaining signed informed consent by the University of Wisconsin IRB.

\section{Bone Health Assessment}

Bone health assessment was performed by a bone health specialist physician or physician assistant coordinator in our fracture liaison service. Patients underwent a comprehensive history, review of risk factors for osteoporosis, fracture history, and laboratory tests. At the time of surgery scheduling, patients were asked to consume 2000 $5000 \mathrm{IU}$ of vitamin D and $1200 \mathrm{mg}$ /day of calcium. During bone health assessment, there was discussion of fall prevention, the potential to improve surgical outcomes in osteoporotic patients, and the need to modify risk factors, such as elimination of toxins. Antiosteoporosis medication was offered to patients only if they met criteria for osteoporosis. Our preference in this cohort was to offer anabolic medications. However, other considerations regarding whether medication was offered and which type was prescribed depended on comorbidities, past use of medications, costs, osteoporosis severity, and patient preferences.

As part of bone health assessment, DXA was performed, and 10-year Fracture Risk Assessment Tool (FRAX) scores of hip fracture and major osteoporotic fracture (MOF) were calculated with and without BMD. A FRAX score was considered high based on a 10-year MOF risk $\geq 20 \%$ or a 10 -year hip fracture risk $\geq 3 \% .^{11-13}$ In patients who underwent DXA at our facility, the FRAX score was adjusted using the trabecular bone score (TBS). ${ }^{13,14}$ TBS was classified as values $<1.23$ indicating degraded bone, values between 1.23 and 1.31 indicating partially degraded bone, and values $>1.31$ indicating intact bone..$^{14}$ The FRAX score was also adjusted by substituting spine BMD for femoral neck BMD. Vertebral fracture assessment (VFA) was obtained in 48 patients and TBS in 73 patients. The VFA was positive only for moderate and severe fractures according to the criteria of Genant et al. ${ }^{15}$ Opportunistic CT scans to measure mean Hounsfield units (HU) at L1 were available for 32 patients.

Bone status was determined using the WHO criteria based on T-score: a T-score $\leq-2.5$ indicates osteoporosis, a T-score of -1.0 to -2.4 indicates osteopenia, and a Tscore $>-1.0$ indicates normal bone status. ${ }^{11}$ In addition, the National Osteoporosis Foundation (NOF) and National Bone Health Alliance classifications were applied, thereby defining osteoporosis as any of the following: T-score $\leq$ -2.5 ; hip or spine fracture; and T-score $\leq-1.0$ to -2.4 with a FRAX 10 -year hip fracture risk $\geq 3 \%$ or MOF risk $\geq$ $20 \% .^{11}$

\section{Statistical Analysis}

Comparison between groups was performed with ANOVA and the Student t-test using Microsoft Excel (version 16.6). A significance level of $p<0.05$ was chosen.

\section{Results}

One hundred four patients were referred for BHO, of whom 84 were females (Table 1). The mean patient age was 69.0 (SD 8.1) years. All patients were Caucasian except 2 reporting Asian ancestry. The mean BMI $\left(\mathrm{kg} / \mathrm{m}^{2}\right)$ was 27.6 (SD 5.8) with 6 patients having a BMI $<20$ and 12 having a $\mathrm{BMI} \geq 35$. Seven patients were using tobacco, and 3 reported using $\geq 3$ alcohol units per day. 
TABLE 1. Demographics and risk factors for osteoporosis

\begin{tabular}{lc}
\hline & Value \\
\hline Mean age in yrs (SD) & $69.0(8.1)$ \\
\hline Female/male, $\mathrm{n}$ & $84 / 20$ \\
\hline Mean BMI in $\mathrm{kg} / \mathrm{m}^{2}(\mathrm{SD})$ & $27.6(5.8)$ \\
\hline Caucasian/Asian race, $\mathrm{n}$ & $102 / 2$ \\
\hline Tobacco use, $\mathrm{n}$ & 7 \\
\hline Alcohol $\geq 3$ U/day, $\mathrm{n}$ & 3 \\
\hline Comorbidities, $\mathrm{n}$ & \\
\hline Diabetes & 15 \\
\hline Inflammatory arthritis & 14 \\
\hline Chronic renal failure & 16 \\
\hline Use of steroids, $\geq 5 \mathrm{mg} / \mathrm{day}$ & \\
\hline Historical height loss in $\mathrm{cm}(\mathrm{n}=83)$ & $5.6(3.0)$ \\
\hline Mean $(\mathrm{SD})$ & $11(13.2)$ \\
\hline$<2, \mathrm{n}(\%)$ & $24(28.9)$ \\
\hline $2-4, \mathrm{n}(\%)$ & $48(57.8)$ \\
\hline$>4, \mathrm{n}(\%)$ & $17(16.3)$ \\
\hline Parental hip fracture, $\mathrm{n}(\%)$ & $56(53.8)$ \\
\hline History of fracture, $\mathrm{n}(\%)$ & $15(14.4)$ \\
\hline History of spine fracture, $\mathrm{n}(\%)$ & $42.4(14.5)$ \\
\hline Mean $25(\mathrm{OH}) \mathrm{D}$ in $\mathrm{ng} / \mathrm{ml}(\mathrm{SD})$ &
\end{tabular}

Historical height loss was available in 83 patients. The mean height loss was 5.6 (SD 3.0) $\mathrm{cm}$. Forty-eight patients $(58 \%)$ had historical height loss $\geq 4 \mathrm{~cm}$, which exceeds NOF recommendations for vertebral imaging. ${ }^{11}$ Another 24 patients had a 2 - to 4 -cm height loss.

Fractures had occurred in 56 patients (53.8\%); 26 had 1, 16 had 2,9 had 3 , and 5 patients had 4 or more prior fractures. Fifteen patients (14.4\%) had prior spinal fractures. Seventeen patients reported a parent with a hip fracture.

The 25-hydroxy vitamin D [25(OH)D] level was measured in 101 patients at the time of BHO clinic consultation. At the time of surgical consultation, patients were advised to consume 2000-5000 IU, which was 2-4 weeks earlier. The mean 25(OH)D was 42.4 (SD 14.5) ng/ml. Overall, 82 patients $(81.1 \%)$ were vitamin D replete $(\geq 30$ $\mathrm{ng} / \mathrm{ml}), 15 \mathrm{had}$ insufficient levels (20-30 $\mathrm{ng} / \mathrm{ml})$, and only 4 had deficient levels $(\leq 20 \mathrm{ng} / \mathrm{ml})$. Hyperparathyroidism was present in 4 patients.

Medical comorbidities that affect bone metabolism

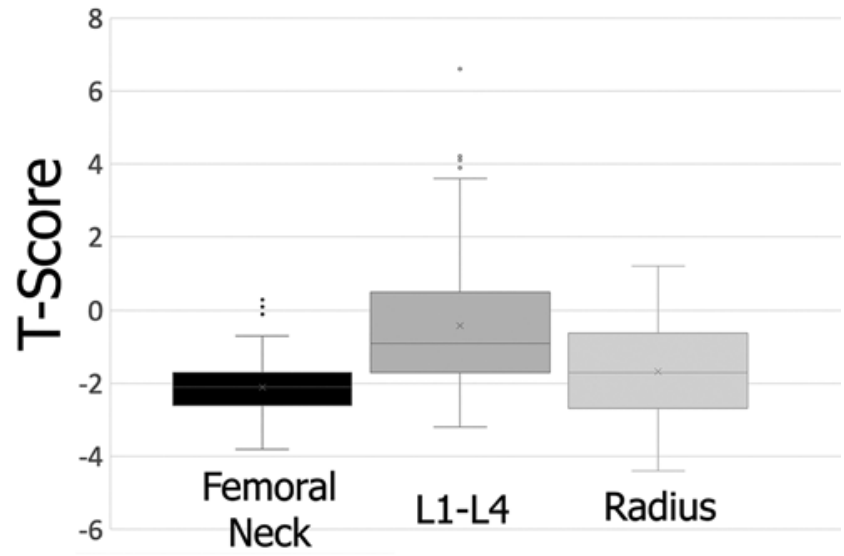

FIG. 1. DXA T-scores of the femoral neck, lumbar spine (L1-4), and one-third distal radius.

were common, including stage 3 or worse chronic renal disease in 8 patients, diabetes in 15 patients, and inflammatory arthritis in 14 patients. In addition, 16 patients were using $\geq 5 \mathrm{mg} /$ day of glucocorticoid medication. Overall, $51 \%$ of patients had secondary osteoporosis.

DXA was performed in 103 patients (Table 2). The mean hip T-score was -2.09 (SD 0.71) in 99 patients, that for the lumbar spine (L1-4) was -0.54 (1.71) in 90 patients, and that for the distal one-third radius was -1.65 (1.38) in 81 patients (Fig. 1). The T-scores were significantly different between sites $(\mathrm{p}<0.05)$. The VFA showed 5 cases of occult fracture and was negative in 43 cases. The TBS indicated degraded microarchitecture in 24 patients, partially degraded microarchitecture in 19 patients, and intact in 30 patients (Table 3).

The 10-year FRAX hip and MOF scores were determined with and without BMD and were used to aid in treatment decisions per NOF guidelines (Table 4). ${ }^{11}$ The mean FRAX hip fracture score was 6.9\% (SD 5.7\%) and the MOF score was $20.7 \%$ (8.9\%). Overall, 80 patients had $\mathrm{a} \geq 3 \%$ risk of hip fracture, 52 patients had $\geq 20 \% \mathrm{MOF}$ risk, and 83 patients had either MOF risk $\geq 20 \%$ or hip fracture risk $\geq 3 \%$. The mean MOF FRAX score without BMD was $19.5 \%(9.8 \%)$, which was not significantly different from FRAX with BMD ( $p>0.05$ ).

The FRAX score adjusted with TBS resulted in a decreased risk of hip fracture (to 2.6\%) and decreased risk of MOF (to $12.9 \%$ ), which were significantly lower than when using hip BMD. Similarly, the spine BMD-adjusted

TABLE 2. DXA T-scores

\begin{tabular}{lcccc}
\hline & Femoral Neck & Lumbar Spine & 1/3 Distal Radius & Lowest T-Score \\
\hline No. of patients & 99 & 90 & 81 & 103 \\
\hline T-score & & & & \\
\hline Mean (SD) & $-2.09(0.71)$ & $-0.54(1.71)$ & $-1.65(1.38)$ & $-2.32(0.88)$ \\
\hline$\leq-2.5$ & 32 & 11 & 24 & 48 \\
\hline$\leq-1.0$ to -2.4 & 62 & 35 & 28 & 50 \\
\hline$>-1.0$ & 5 & 44 & 29 & 6 \\
\hline
\end{tabular}

Values represent the number of patients unless stated otherwise. 
TABLE 3. Results of VFA, TBS, and opportunistic CT

\begin{tabular}{cc}
\hline & Value \\
\hline VFA & \\
\hline No. of patients & 48 \\
\hline Fractured & 5 \\
\hline Not fractured & 43 \\
\hline TBS & 73 \\
\hline No. of patients & $1.28(0.11)$ \\
\hline Mean (SD) & 30 \\
\hline Normal & 19 \\
\hline Partially degraded & 24 \\
\hline Degraded & 32 \\
\hline Opportunistic CT & $113.0(44.8)$ \\
\hline No. of patients & 18 \\
\hline Mean (SD) HU at L1 & 6 \\
\hline$\leq 110$ HU & \\
\hline$\geq 150$ HU &
\end{tabular}

Values represent the number of patients unless stated otherwise.

FRAX score was significantly lower than when hip BMD was used $(p<0.05$, Table 4$)$.

Opportunistic CT scans that could measure L1 HU were available in 32 patients. The mean L1 HU was 113.0 (SD 44.8, range 29-260). Using a threshold of $\leq 110 \mathrm{HU}$ to establish osteoporosis, 18 patients $(56.3 \%)$ were likely to have and only 6 had what is considered normal bone $(\mathrm{HU} \geq 150)$.

The bone status using WHO criteria was osteoporotic in $33(32.1 \%)$, osteopenic in $61(59.2 \%)$, and normal in 9 (8.7\%) (Table 5). Using the NOF criteria resulted in classifying osteoporosis in 84 patients $(81.6 \%)$.

Pharmaceutical medications were recommended in 75 patients (72\%). Anabolic therapy was prescribed in 44 patients (42\%) (abaloparatide or teriparatide), and antiresorptive therapy was prescribed in $31(30 \%)$ (alendronate, risedronate, zoledronic acid, or denosumab) (Table 5).

\section{Discussion}

This study showed that in patients referred for $\mathrm{BHO}$, decreased BMD and abnormal bone microarchitecture were common. The majority of patients $(81.6 \%)$ met NOF criteria for osteoporosis treatment, and $73 \%$ of all pursued therapy. A history of one or more prior fractures was com-
TABLE 5. Bone classification and treatment

\begin{tabular}{lc}
\hline & Value \\
\hline WHO & \\
\hline Osteoporosis, T-score $\leq-2.5$ & $32.1 \%$ \\
\hline Low bone mass, T-score $\leq-1$ to -2.4 & $59.2 \%$ \\
\hline Normal, T-score $>-1.0$ & $8.7 \%$ \\
\hline NOF recommendations & $81.6 \%$ \\
\hline Osteoporosis & $18.4 \%$ \\
\hline No osteoporosis & \\
\hline Pharmaceutical treatment, $n$ & 30 \\
\hline Anabolic & 14 \\
\hline Teriparatide & 30 \\
\hline Abaloparatide & 1 \\
\hline Antiresorptive &
\end{tabular}

mon. We also found that the FRAX assessment, with or without femoral neck BMD, was useful in categorizing risk. The finding of a high prevalence of decreased bone health in a spine surgery patient population highlights the need for surgeons to consider bone health assessment before an elective surgical procedure.

Patients were referred by their spine surgeons for preoperative BHO based on history, physical examination, and review of radiographs. These factors are available to all spine surgeons. Identification of prior fractures is simple by history but also using imaging and performing VFA during DXA. The presence of a spine fragility fracture indicates that the patient has osteoporosis per NOF recommendations and would likely be at risk for osteoporosis-related complications (Fig. 2A). ${ }^{11}$ Other risk factors such as inflammatory arthritis and the use of medication such as corticosteroids are associated with decreased bone strength and should prompt further investigation of bone health. Historical height change is easily overlooked and correlates strongly to the severity of bone disease in the general population. ${ }^{16} \mathrm{~A}$ recent $2-\mathrm{cm}$ change in height or a historical change of $4 \mathrm{~cm}$ warrants spinal imaging per NOF guidelines. ${ }^{11}$ In spine patients, height change may also represent progressive deformity that in itself may be associated with osteoporosis. ${ }^{17}$ In our opinion, a preoperative patient with a recent $2-\mathrm{cm}$ change in height or historical 4-cm height loss should undergo DXA. Using

TABLE 4. FRAX score

\begin{tabular}{|c|c|c|c|c|c|c|}
\hline & \multirow{2}{*}{$\begin{array}{c}\text { No. of } \\
\text { Patients }\end{array}$} & \multicolumn{2}{|c|}{ 10-Yr Hip Fracture Risk } & \multicolumn{2}{|c|}{ 10-Yr MOF Risk } & \multirow{2}{*}{$\begin{array}{c}\text { No. of Patients } \\
\text { Exceeding Criteria of } \\
\geq 3 \% \text { Hip or } \geq 20 \% \text { MOF }\end{array}$} \\
\hline & & Mean \% (SD) & No. of Patients $w / \geq 3 \%$ & Mean \% (SD) & No. of Patients $w / \geq 20 \%$ & \\
\hline w/ femoral neck BMD & 99 & $6.9(5.7)$ & $80(80.8 \%)$ & $20.7(8.9)$ & $52(52.5 \%)$ & $82(82.8 \%)$ \\
\hline w/ BMD & 104 & $6.8(6.7)$ & $69(66.3 \%)$ & $19.5(9.8)$ & $44(42.3 \%)$ & $72(69.2 \%)$ \\
\hline w/ lumbar spine BMD & 72 & $2.4(3.0)$ & $21(29.2 \%)$ & $12.5(7.8)$ & $9(12.5 \%)$ & $23(31.9 \%)$ \\
\hline w/ TBS adjustment & 72 & $2.6(3.1)$ & $21(29.2 \%)$ & $12.9(7.5)$ & $10(13.9 \%)$ & $21(29.2 \%)$ \\
\hline
\end{tabular}



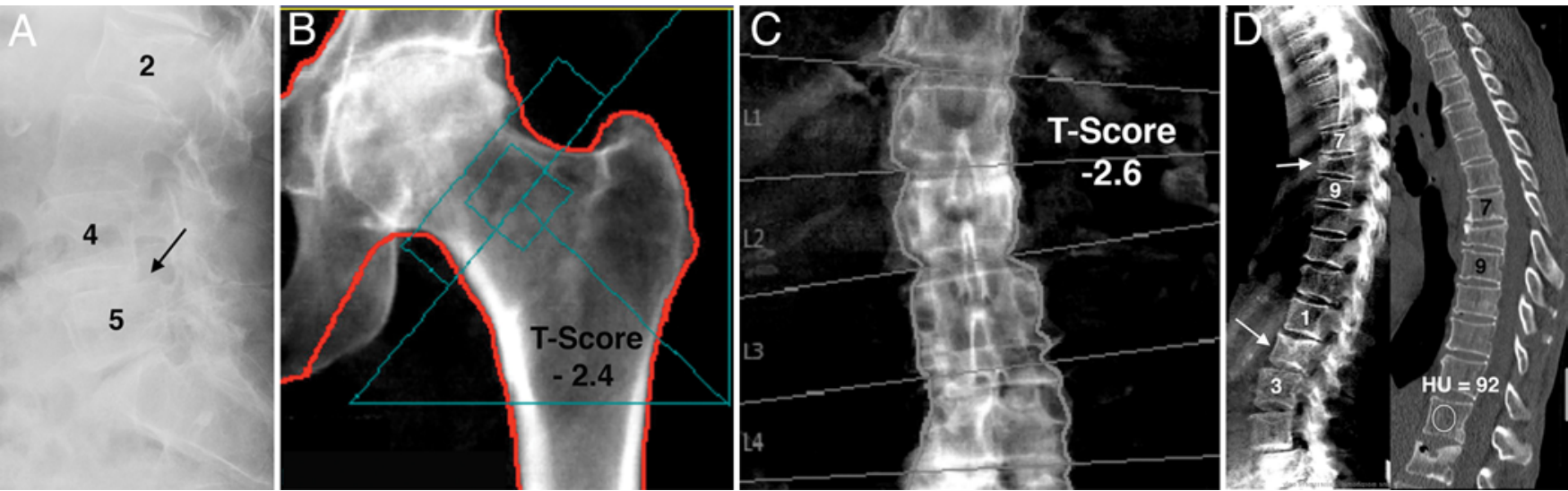

FIG. 2. A: A 78-year-old female patient presented with neurogenic claudication from increasing degenerative scoliosis and spondylolisthesis at L4-5 (arrow). A compression fracture is present at L2. She had a history of right hip fracture treated with an intramedullary nail 6 years earlier and was found to be "osteopenic" and was treated for 2 years with alendronate. Her BMI was 19.5, and she had lost $37 \mathrm{~mm}$ in height. B: A DXA scan showed a left total hip T-score of -2.4 . This was invalid due to osteoarthritis. C: The T-score of the lumbar spine (L1-4) was -2.6 but was also invalid due to degenerative changes at $L 4-5$ and $L 2-3$. The microarchitecture of the patient's lumbar spine TBS was degraded. The one-third distal radius DXA T-score was -3.6. D: VFA (left) showed old fractures at T8 and L2 (arrows). A sagittal chest CT scan (right) from 6 years earlier demonstrated the old fractures. The HU (ellipse) at L1 was 92. A diagnosis of osteoporosis was made, and teriparatide was administered. After discussion of the risk of surgery, the patient is attempting further nonoperative care. A DXA scan obtained 18 months after teriparatide showed a lumbar spine BMD increase by $8 \%$ (not shown).

all of these measures, more than $80 \%$ of these patients had osteoporosis and were candidates for pharmaceutical treatment.

Vitamin D is needed for calcium absorption from the gut, mineralization of osteoid matrix, and collagen crosslinking and is almost always universally deficient in spine surgery patients. ${ }^{18-21}$ Correction is rarely performed, and deficiency is related to poorer outcomes. ${ }^{18,20,22-24}$ Correction of vitamin D deficiency is simple and well within the skill set of all spine surgeons; asking patients to use 20005000 IU daily vitamin D3 at the time of surgery assessment is simple, inexpensive, and virtually side-effect free. With this approach, we were surprised that the vast majority of patients were vitamin D replete by the time of BHO.

Bone strength is related to BMD and bone quality. Bone quality is associated with mineralization, collagen organization, and bone microarchitecture. BMD is measured by DXA and can also be estimated by opportunistic $\mathrm{CT} .{ }^{25}$ DXA provides a reliable method to assess BMD but can have errors and misinterpretations (Fig. 2B and C). ${ }^{26}$ To classify bone health, the lowest femoral neck T-score rather than that of the spine (especially in spine surgery candidates) or, alternatively, the lowest T-score from any site should be used. ${ }^{11}$ The International Society for Clinical Densitometry recommends when assessing lumbar spine BMD that only spine segments without artifact or deformity should be used, assessment must include at least 2 segments, and no single segment should have greater than 1 standard deviation difference than any other. ${ }^{27}$ This guideline was confirmed in the current study, as the femoral neck T-score was 1.5 standard deviations lower than that of the lumbar spine. This also translated into change of bone classification, where the FRAX 10-year MOF risk was $20.7 \%$ with femoral neck BMD and only $12.5 \%$ with spine BMD. Using spine BMD to estimate risk or classify bone health in spine surgery patients will lead to underestimation of disease.

The diagnosis of osteoporosis, and thus indications for management, has undergone change from using the WHO classification based on BMD to including function such as presence of hip or spine fractures and predictions of fracture risk. ${ }^{11,12}$ The latter method has been advocated since T-scores $\leq-2.5$ are present in less than half of the cases of hip and spine fragility fracture. ${ }^{11,12}$ This finding is consistent with our results because only one-third of our patients had osteoporosis by WHO criteria compared with more than $80 \%$ by NOF criteria. In our BHO program, the expanded criteria were used to determine who should have pharmaceutical treatment.

Advanced densitometry, including VFA, TBS, and opportunistic CT, were utilized. VFA provides a lateral image from T3 to L5 that is used to identify prevalent spinal fractures (Fig. 2D). Depending on the population studied, spinal fractures can be seen in $30 \%$ of patients, many of which are occult. ${ }^{11}$ Prevalent fractures are important in patients being considered for spine surgery, although in this study the percentage was relatively low, given the high percentage of patients with osteoporosis. The TBS measures textural variations using variation of the gray level on lumbar DXA. ${ }^{14}$ It is an index of bone microarchitecture and correlates to the number and connectivity of trabeculae. The TBS was abnormal in almost two-thirds of our patients, although it did not affect the FRAX score. Since TBS relates to bone microarchitecture, it is a better predictor of fracture than BMD, and therefore it might help to assess how screws and interbody devices are likely to perform. ${ }^{28,29}$ TBS has been shown to be useful, even in the presence of degenerative changes in the lumbar spine, although - in this study-TBS tracked with spine BMD better than hip BMD. ${ }^{30}$ Opportunistic CT is easy to perform 
using existing CT data obtained for any purpose. ${ }^{25} \mathrm{An}$ $\mathrm{L} 1 \mathrm{HU} \leq 110$ indicates a high likelihood of osteoporosis, while one of $\geq 150$ indicates normal bone. ${ }^{25,31} \mathrm{HU}$ values $<100$ have been associated with cage subsidence, pedicle screw loosening, and proximal junctional kyphosis and fracture ${ }^{32-34}$ Low HU indicating an osteoporotic condition may also predict poorer union after fusion. ${ }^{35}$

The optimal timing and which medication should be used for preoperative optimization is unknown. There is evidence that both antiresorptive agents (oral and parenteral forms of bisphosphonates and denosumab) result in better outcomes and fewer complications than placebo. ${ }^{36-38}$ Similarly, teriparatide, an anabolic agent, has been shown to speed fusion and reduce hardware complications in spine surgery. ${ }^{36,39-41}$ We prefer anabolic medications, but these were only used in half of our cases. Surgeons are concerned that antiresorptive agents will impair spinal fusion. However, adverse effects of antiresorptive medications on spinal fusion have not been reported, and, in fact, multiple studies have shown equal or better results. ${ }^{42-45}$ Surgical delay was not reported in the current study because many patients were not given surgical dates until after bone health assessment and initiation of treatment was concluded. In general, our approach for any osteoporotic patient was to administer at least 3 months of pharmaceutical treatment before surgery, if possible. In 5 cases, surgery was not performed largely due to severity of bone disease.

Other limitations of this study were that it was not designed to determine the efficacy of preoperative BHO. We do not know if our treatment resulted in better outcomes and lower complications. Further research is clearly needed. Our patients were surgeon selected and therefore other patients with osteoporosis may have been missed. The recently published International Society for Clinical Densitometry position statement to identify who should undergo DXA before surgery was not available at the time of this study but, hopefully, it will aid in the identification of atrisk patients who may benefit from screening and preoperative $\mathrm{BHO} .{ }^{10}$ Our population was from a tertiary referral academic center, and the majority of patients were older Caucasian adults. Since osteoporosis has a racial, age, and sex influence, results may not apply to all populations.

\section{Conclusions}

Preoperatively, surgeons are able to identify patients with potential poor bone health using easily applied criteria. DXA should be interpreted using femoral neck or total hip BMD and not the spine T-score in the presence of deformity or degeneration, and the FRAX score should be calculated. If available, newer technologies, including VFA and TBS, can aid in estimation of bone health. Four to 5 weeks of 2000-5000 IU daily vitamin D3 supplementation started at the time of surgery scheduling will result in the majority of patients being replete. Referral to a bone health specialist or fracture liaison-type service is suggested for patients 50 years of age or older with suspected poor bone health for comprehensive care, including correction of modifiable risk factors and pharmaceutical treatment.

\section{References}

1. Dietz N, Sharma M, Adams S, et al. Enhanced recovery af- ter surgery (ERAS) for spine surgery: a systematic review. World Neurosurg. 2019;130:415-426.

2. Dagal A, Bellabarba C, Bransford R, et al. Enhanced perioperative care for major spine surgery. Spine (Phila Pa 1976). 2019;44(13):959-966.

3. Anderson PA, Savage JW, Vaccaro AR, et al. Prevention of surgical site infection in spine surgery. Neurosurgery. 2017;80(3S):S114-S123.

4. Sethi R, Buchlak QD, Yanamadala V, et al. A systematic multidisciplinary initiative for reducing the risk of complications in adult scoliosis surgery. J Neurosurg Spine. 2017;26(6):744750 .

5. Dipaola CP, Bible JE, Biswas D, et al. Survey of spine surgeons on attitudes regarding osteoporosis and osteomalacia screening and treatment for fractures, fusion surgery, and pseudoarthrosis. Spine J. 2009;9(7):537-544.

6. Kuprys TK, Steinmetz LM, Fischer CR, et al. Preoperative assessment of bone quality in spine deformity surgery: correlation with clinical practice and published recommendations. Spine (Phila Pa 1976). 2019;44(12):E735-E741.

7. Schmidt T, Ebert K, Rolvien T, et al. A retrospective analysis of bone mineral status in patients requiring spinal surgery. BMC Musculoskelet Disord. 2018;19(1):53.

8. Bjerke BT, Zarrabian M, Aleem IS, et al. Incidence of osteoporosis-related complications following posterior lumbar fusion. Global Spine J. 2018;8(6):563-569.

9. Anderson PA, Jeray KJ, Lane JM, Binkley NC. Bone health optimization: beyond own the bone: AOA Critical Issues. $J$ Bone Joint Surg Am. 2019;101(15):1413-1419.

10. Anderson PA, Morgan SL, Krueger D, et al. Use of bone health evaluation in orthopedic surgery: 2019 ISCD Official Position. J Clin Densitom. 2019;22(4):517-543.

11. Cosman F, de Beur SJ, LeBoff MS, et al. Clinician's guide to prevention and treatment of osteoporosis. Osteoporos Int. 2014;25(10):2359-2381.

12. Camacho PM, Petak SM, Binkley N, et al. American Association of Clinical Endocrinologists and American College of Endocrinology Clinical Practice Guidelines for the Diagnosis and Treatment of Postmenopausal Osteoporosis - 2016. Endocr Pract. 2016;22(4)(suppl 4):1-42.

13. Hans DB, Kanis JA, Baim S, et al. Joint Official Positions of the International Society for Clinical Densitometry and International Osteoporosis Foundation on FRAX ${ }^{\circledR}$. Executive Summary of the 2010 Position Development Conference on Interpretation and use of FRAX ${ }^{\circledast}$ in clinical practice. J Clin Densitom. 2011;14(3):171-180.

14. Hans D, Goertzen AL, Krieg MA, Leslie WD. Bone microarchitecture assessed by TBS predicts osteoporotic fractures independent of bone density: the Manitoba study. J Bone Miner Res. 2011;26(11):2762-2769.

15. Genant HK, Jergas M, Palermo L, et al. Comparison of semiquantitative visual and quantitative morphometric assessment of prevalent and incident vertebral fractures in osteoporosis The Study of Osteoporotic Fractures Research Group. J Bone Miner Res. 1996;11(7):984-996.

16. Mikula AL, Hetzel SJ, Binkley N, Anderson PA. Validity of height loss as a predictor for prevalent vertebral fractures, low bone mineral density, and vitamin D deficiency. Osteoporos Int. 2017;28(5):1659-1665.

17. Yu WS, Chan KY, Yu FW, et al. Abnormal bone quality versus low bone mineral density in adolescent idiopathic scoliosis: a case-control study with in vivo high-resolution peripheral quantitative computed tomography. Spine $J$. 2013;13(11):1493-1499.

18. Stoker GE, Buchowski JM, Bridwell KH, et al. Preoperative vitamin D status of adults undergoing surgical spinal fusion. Spine (Phila Pa 1976). 2013;38(6):507-515.

19. Stoker GE, Buchowski JM, Chen CT, et al. Hypovitaminosis $\mathrm{D}$ and cervical disk herniation among adults undergoing spine surgery. Global Spine J. 2013;3(4):231-236. 
20. Ravindra VM, Godzik J, Guan J, et al. Prevalence of vitamin $\mathrm{D}$ deficiency in patients undergoing elective spine surgery: a cross-sectional analysis. World Neurosurg. 2015;83(6):11141119.

21. Kim TH, Lee BH, Lee HM, et al. Prevalence of vitamin D deficiency in patients with lumbar spinal stenosis and its relationship with pain. Pain Physician. 2013;16(2):165-176.

22. Kim TH, Yoon JY, Lee BH, et al. Changes in vitamin D status after surgery in female patients with lumbar spinal stenosis and its clinical significance. Spine (Phila Pa 1976). 2012;37(21):E1326-E1330.

23. Ravindra VM, Godzik J, Dailey AT, et al. Vitamin D levels and 1-year fusion outcomes in elective spine surgery: a prospective observational study. Spine (Phila Pa 1976). 2015;40(19):1536-1541.

24. Ravindra VM, Guan J, Holland CM, et al. Vitamin D status in cervical spondylotic myelopathy: comparison of fusion rates and patient outcome measures. A preliminary experience. J Neurosurg Sci. 2019;63(1):36-41.

25. Anderson PA, Polly DW, Binkley NC, Pickhardt PJ. Clinical use of opportunistic computed tomography screening for osteoporosis. J Bone Joint Surg Am. 2018;100(23):2073-2081.

26. Krueger D, Shives E, Siglinsky E, et al. DXA errors are common and reduced by use of a reporting template. J Clin Densitom. 2019;22(1):115-124.

27. Lewiecki EM, Binkley N, Morgan SL, et al. Best practices for dual-energy X-ray absorptiometry measurement and reporting: International Society for Clinical Densitometry Guidance. J Clin Densitom. 2016;19(2):127-140.

28. Krueger D, Fidler E, Libber J, et al. Spine trabecular bone score subsequent to bone mineral density improves fracture discrimination in women. J Clin Densitom. 2014;17(1):60-65.

29. McCloskey EV, Odén A, Harvey NC, et al. A meta-analysis of trabecular bone score in fracture risk prediction and its relationship to FRAX. J Bone Miner Res. 2016;31(5):940-948.

30. Anderson KB, Holloway-Kew KL, Mohebbi M, et al. Is trabecular bone score less affected by degenerative-changes at the spine than lumbar spine BMD? Arch Osteoporos. 2018;13(1):127.

31. Lee SJ, Binkley N, Lubner MG, et al. Opportunistic screening for osteoporosis using the sagittal reconstruction from routine abdominal CT for combined assessment of vertebral fractures and density. Osteoporos Int. 2016;27(3):1131-1136.

32. Mi J, Li K, Zhao X, et al. Vertebral body Hounsfield units are associated with cage subsidence after transforaminal lumbar interbody fusion with unilateral pedicle screw fixation. Clin Spine Surg. 2017;30(8):E1130-E1136.

33. Bredow J, Boese CK, Werner CM, et al. Predictive validity of preoperative CT scans and the risk of pedicle screw loosening in spinal surgery. Arch Orthop Trauma Surg. 2016;136(8):1063-1067.

34. Meredith DS, Schreiber JJ, Taher F, et al. Lower preoperative Hounsfield unit measurements are associated with adjacent segment fracture after spinal fusion. Spine (Phila Pa 1976). 2013;38(5):415-418.

35. Schreiber JJ, Hughes AP, Taher F, Girardi FP. An association can be found between Hounsfield units and success of lumbar spine fusion. HSS J. 2014;10(1):25-29.

36. Stone MA, Jakoi AM, Iorio JA, et al. Bisphosphonate's and intermittent parathyroid hormone's effect on human spinal fusion: a systematic review of the literature. Asian Spine J. 2017;11(3):484-493.
37. Hirsch BP, Unnanuntana A, Cunningham ME, Lane JM. The effect of therapies for osteoporosis on spine fusion: a systematic review. Spine J. 2013;13(2):190-199.

38. McCoy S, Tundo F, Chidambaram S, Baaj AA. Clinical considerations for spinal surgery in the osteoporotic patient: a comprehensive review. Clin Neurol Neurosurg. 2019;180:4047.

39. Liu Y, Levack AE, Marty E, et al. Anabolic agents: what is beyond osteoporosis? Osteoporos Int. 2018;29(5):1009-1022.

40. Ebata S, Takahashi J, Hasegawa T, et al. Role of weekly teriparatide administration in osseous union enhancement within six months after posterior or transforaminal lumbar interbody fusion for osteoporosis-associated lumbar degenerative disorders: a multicenter, prospective randomized study. $J$ Bone Joint Surg Am. 2017;99(5):365-372.

41. Ohtori S, Inoue G, Orita S, et al. Teriparatide accelerates lumbar posterolateral fusion in women with postmenopausal osteoporosis: prospective study. Spine (Phila Pa 1976). 2012;37(23):E1464-E1468.

42. Buerba RA, Sharma A, Ziino C, et al. Bisphosphonate and teriparatide use in thoracolumbar spinal fusion: a systematic review and meta-analysis of comparative studies. Spine (Phila Pa 1976). 2018;43(17):E1014-E1023.

43. Chen F, Dai Z, Kang Y, et al. Effects of zoledronic acid on bone fusion in osteoporotic patients after lumbar fusion. $O s$ teoporos Int. 2016;27(4):1469-1476.

44. Liu WB, Zhao WT, Shen P, Zhang FJ. The effects of bisphosphonates on osteoporotic patients after lumbar fusion: a meta-analysis. Drug Des Devel Ther. 2018;12:2233-2240.

45. Park YS, Kim HS, Baek SW, et al. The effect of zoledronic acid on the volume of the fusion-mass in lumbar spinal fusion. Clin Orthop Surg. 2013;5(4):292-297.

\section{Disclosures}

Dr. Anderson: consultant for Amgen, Radius Medical, and Medtronic; direct stock ownership in Titan Spine; royalties from Regeneration Technologies; and support of non-study-related clinical or research effort from Radius Medical. Dr. Binkley: support of non-study-related clinical or research effort from Radius.

\section{Author Contributions}

Conception and design: Anderson, Binkley. Acquisition of data: all authors. Analysis and interpretation of data: Anderson, Kadri, Binkley. Drafting the article: Anderson, Binkley. Critically revising the article: all authors. Reviewed submitted version of manuscript: Anderson, Binkley. Approved the final version of the manuscript on behalf of all authors: Anderson. Statistical analysis: Anderson, Kadri. Administrative/technical/material support: Anderson, Hare, Binkley. Study supervision: Anderson, Binkley.

\section{Correspondence}

Paul A. Anderson: University of Wisconsin, Madison, WI. anderson@ortho.wisc.edu. 